\title{
ANALISIS ARUS INRUSH SAAT SWITCHING KAPASITOR BANK PADA BUSBAR 2 (Suatu Studi DI PT.PLN (persero) GARDU INDUK GANDUL) \\ ${ }^{1}$ Irfan Hidayat, ${ }^{2}$ Nur Hanifah Yuninda, ${ }^{3}$ Imam Arif Raharjo. \\ 1.2.3 Pendidikan Teknik Elektro, Fakultas Teknik, Universitas Negeri Jakarta \\ 1.2.3 Email : irfan.hidayat56@gmail.com; hanifah@unj.ac.id; imam_ar@unj.ac.id
}

\begin{abstract}
Irfan Hidayat, Analysis of Inrush Flow when Switching Bank Capacitors on Busbar 2. Thesis. Jakarta, Electrical Engineering Education Study Program, Faculty of Engineering, Jakarta State University 2018. Supervisor: Nur Hanifah Yuninda, ST., MT., And Imam Arif Raharjo, S.Pd., MT. This study aims to analyze the inrush current when switching bank capacitors. The inrush current can be defined as the magnitude of the current surge that first appears in the circuit, when the circuit is connected to the load. As with transient phenomena, inrush currents in electrical circuits are considered undesirable. In every electrical equipment there must be an inrush current. The inrush current is dangerous for the system when the peak value of the inrush current is very large. To reduce the value of inrush current using a series reactor. The research method used in this study is the experimental method using a research design with pre-experimental design used is one-group pretest-posttest design. In collecting data, the circuit inductance data is collected and on the bank capacitors. To analyze how much the inrush current and frequency before and after the addition of a series reactor. The results showed inrush current when switching capacitor banks before the addition of series reactors exceeded the IEEE Std C37.012-2005 standard where the inrush current is allowed 100 times the rms current. The value of the inrush current and frequency at each step before the addition of the series reactor is: step $1=16.29 \mathrm{kA}, 4.16 \mathrm{kHz}$; Step $2=289.7 \mathrm{kA}, 147.32 \mathrm{kHz}$; Step $3=$ $349.22 \mathrm{kA}, 133.2 \mathrm{kHz}$; Step $4=372.47 \mathrm{kA}, 126.28 \mathrm{kHz}$; Step $5=386.03 \mathrm{kA}, 122.7 \mathrm{kHz}$; Step $6=410.146 \mathrm{kA}$, $125.15 \mathrm{kHz}$. The value of the inrush current and frequency at each step after the addition of the series reactor is: step $1=1.1 \mathrm{kA}, 0.2 \mathrm{kHz}$; Step $2=26.56 \mathrm{kA}, 13.5 \mathrm{kHz}$; Step $3=30.68 \mathrm{kA}, 11.7 \mathrm{kHz}$; Step $4=36.35 \mathrm{kA}, 12.3 \mathrm{kHz}$; Step $5=41.08 \mathrm{kA}, 13.05 \mathrm{kHz}$; Step $6=45.27 \mathrm{kA}, 13.8 \mathrm{kHz}$. So that the inrush current is in accordance with the IEEE Std C37.012-2005 standard.
\end{abstract}

Keywords: Inrush Flow, Switching, Frequency, Series Reactor.

\begin{abstract}
Abstrak
Irfan Hidayat, Analisis Arus Inrush saat Switching Kapasitor Bank pada Busbar 2. Skripsi. Jakarta, Program Studi Pendidikan Teknik Elektro Fakultas Teknik Universitas Negeri Jakarta 2018. Dosen Pembimbing: Nur Hanifah Yuninda, ST., MT., dan Imam Arif Raharjo, S.Pd., MT. Penelitian ini bertujuan untuk menganalisis arus inrush pada saat switching kapasitor bank. Arus inrush dapat didefinisikan sebagai besarnya lonjakan arus pertama kali muncul pada rangkaian, saat rangkaian terhubung dengan beban. Sama halnya dengan fenomena transien, arus inrush dalam rangkaian listrik dianggap sebagai hal yang tidak diinginkan. Pada setiap peralatan listrik pasti terjadi arus inrush. Arus inrush berbahaya bagi sistem ketika nilai puncak arus inrush terjadi sangat besar. Untuk mereduksi besar nilai arus inrush menggunakan reaktor seri. Metode penelitian yang digunakan pada penelitian ini adalah metode eksperimen menggunakan rancangan penelitian dengan desain pre-experimental yang digunakan adalah one-group pretest-posttest design. Pada pengumpulan data, dilakukan pengambilan data induktansi rangkaian dan pada kapasitor bank. Untuk menganalisis seberapa besar arus inrush dan frekuensi sebelum dan sesudah penambahan reaktor seri. Hasil penelitian menunjukan arus inrush saat switching kapasitor bank sebelum penambahan reaktor seri melebihi standart IEEE Std C37.012-2005 dimana arus inrush yang di ijinkan 100 kali arus rms. Besar nilai arus inrush dan frekuensi pada setiap step sebelum penambahan reaktor seri sebesar: step $1=16,29$ kA, 4,16 kHz; Step $2=289,7$ kA, 147,32 kHz; Step $3=349,22$ kA, 133,2 kHz; Step $4=$ $372,47 \mathrm{kA}, 126,28 \mathrm{kHz}$; Step $5=386,03 \mathrm{kA}, 122,7 \mathrm{kHz}$; Step $6=410,146 \mathrm{kA}, 125,15 \mathrm{kHz}$. Besar nilai arus inrush dan frekuensi pada setiap step setelah penambahan reaktor seri sebesar: step $1=1,1 \mathrm{kA}, 0,2 \mathrm{kHz}$; Step $2=26,56$ kA, 13,5 kHz; Step $3=30,68$ kA, 11,7 kHz; Step 4 = 36,35 kA, 12,3 kHz; Step 5 = 41,08 kA, 13,05 kHz; Step 6 $=45,27 \mathrm{kA}, 13,8 \mathrm{kHz}$. Sehingga arus inrush sesuai dengan standart IEEE Std C37.012-2005.
\end{abstract}

Kata kunci: Arus inrush, Switching, Frekuensi, Reaktor Seri.

\section{I.PENDAHULUAN}

PT. PLN (Persero) merupakan perusahaan milik negara yang berwenang untuk memenuhi kebutuhan listrik di Indonesia, memegang peranan yang sangat penting dalam menjamin kualitas kelistrikan dan memberikan pelayanan terbaik mulai dari penyediaan daya listrik, penyaluran dari pusat pembangkit hingga pendistribusiannya ke pihak pelanggan. Dalam penyaluran tersedianya pasokan 
energi listrik diperlukan Gardu Induk yang mampu berjalan dengan baik. Dimana fungsi Gardu Induk dalam sistem tenaga yaitu mentransformasikan daya listrik dari tegangan tinggi ke tegangan menengah atau sebaliknya dari tegangan menengah ke tegangan tinggi. Di dalam Gardu Induk terdapat banyak bagian-bagian yang membantu kinerja untuk penyaluran energi salah satunya adalah kapasitor bank.

Kapasitor bank berfungsi untuk menyediakan daya reaktif yang digunakan untuk mengkompensasikan kekurangan daya reaktif pada sistem tenaga listrik. Hasil kompensasi daya reaktif ini juga memperkecil jatuh tegangan atau memperbaiki profil tegangan, selain itu mengurangi rugi-rugi dan meningkatkan faktor daya.

Daya reaktif dibutuhkan ketika generator terhubung dengan beban induktif seperti motor listrik, transformator dan juga reaktansi pada konduktor saluran transmisi serta distribusi.

Selain kapasitor bank merupakan komponen yang sangat penting dalam sistem tenaga listrik, namun penyediaan daya reaktif menggunakan kapasitor bank dapat menimbulkan gejala transien berupa arus inrush yang tinggi dan osilasi saat switching kapasitor bank ke sistem. Kejadian transien tersebut dapat membahayakan peralatan listrik selain itu juga dapat berdampak pada tegangan. Kejadian switching kapasitor bank dapat menyebabkan tegangan lebih yang dapat mempengaruhi daya. Permasalahan kualitas daya listrik disebabkan oleh fenomena-fenomena elektromagnetik yang terjadi pada sistem tenaga listrik. Gejala elektromagnetik yang menyebabkan permasalahan kualitas daya salah satunya adalah gejala peralihan (transien), yaitu suatu gejala perubahan tegangan, arus dan lain-lain yang terjadi selama masa transisi dari keadaan mantap (steady state) menjadi keadaan yang lain.

Secara umum kenaikan tegangan saat operasi switching pada kapasitor bank dapat mencapai beberapa kali nilai dari batas standar. Peralatan listrik hanya dapat bertahan sebentar bila mendapatkan besar kenaikan tegangan berulang kali, maka isolasi dari peralatan akan melemah dan kemungkinan terjadi breakdown. Apabila hal ini terjadi maka dapat membahayakan peralatan. Arus inrush ini dapat direduksi dengan menggunakan reaktor dengan nilai induktansi yang sesuai dengan kapasitor bank.
Beberapa penelitian yang telah dilakukan mengenai arus inrush saat switching kapasitor bank. Pertama, Mohammad Adif yang diterbitkan dalam Jurnal Mahasiswa TEUB, Vol.2, No.5, tahun 2014 melakukan penelitian dengan judul "Analisis arus inrush saat switching kapasitor bank di Gardu Induk (GI) Manisrejo Madiun”. Pada penelitian ini saat switching kapasitor bank terjadi lonjakan arus atau arus inrush dan frekuensi osilasi pada setiap step pemasukan kapasitor bank. Besar arus inrush dan frekuensi pada setiap step yakni, step $1=35.634,77 \mathrm{~A}, 0,63256$ kHz; step $2=695.716,00 \mathrm{~A}, 219.8 \mathrm{kHz}$; step 3 $=9.721 .846,50 \mathrm{~A}, 20,69 \mathrm{kHz}$; step $4=$ $129.453 .363,10 \mathrm{~A}, 1,649 \mathrm{kHz}$; step $5=$ 1,244259.1010 A, 0,1258 kHz.

Kedua, penelitian yang dilakukan oleh Fitriyanti Mayasari yang terbitkan dalam Jurnal Ilmiah “Elektrikal Enjiniring” UNHAS, Vol.7, No.1, bulan Januari-April, tahun 2009 dengan pembahasan analisis transient akibat pengaruh switching kapasitor bank dan metode penanggulangannya. Pada penelitian ini tegangan transient disebabkan oleh petir, proses switching dan gangguan yang terjadi dalam sistem tenaga, besaran transien ini tergantung dari timbulnya, nilai maksimumnya, bentuk gelombang dan frekuensi yang terjadi pada sistem tenaga. Akibatnya adalah kerusakan pada peralatan konsumen, kerusakan pada masalah operasi, mempercepat lifetime peralatan dan kerusakan mendadak peralatan.

Ketiga, penelitian yang dilakukan oleh Hendik Eko HS, Yahya Chusna Arif, dan Indhana Sudiharto yang berjudul "Teknik pengurangan arus inrush dan pengurangan harmonisa pada kapasitor bank untuk beban non linier", dengan hasil pembahasan kapasitor bank disamping memperbaiki power factor tetapi juga menimbulkan gangguan kualitas daya yang lain yaitu gangguan osilatory transien pada saat switching kapasitor dan gangguan resonansi bila sistem mengandung harmonisa. Gangguan-gangguan ini dapat merusak peralatan. Arus inrush kapasitor sangat besar bisa mencapai 40 sampai 250 kali I nominal, sehingga perlu dikurangi supaya gangguan transien bisa diperkecil. Pengurangan yang paling 
sederhana adalah menggunakan air coil yang akan menurunkan arus inrush hingga $1 / 4$ nya bila dibandingkan dengan tanpa air coil atau kalau sistem mengandung harmonisa penggunaan filter bisa menurunkan arus inrush.

Dari beberapa penelitian yang pernah dilakukan mengenai arus inrush, gejala transien, dan switching kapasitor bank, penulis memutuskan mengangkat topik untuk menganalisis seberapa besar arus inrush, frekuensi, dan perubahan arus inrush yang terjadi pada saat switching kapasitor bank.

\section{METODE PENELITIAN}

Metode penelitian yang digunakan pada penelitian ini adalah metode eksperimen. Pada penelitian ini menggunakan rancangan penelitian dengan desain pre-experimental yang digunakan adalah one-group pretest-posttest design.

\section{$\mathrm{O}_{1} \mathrm{X} \mathrm{O}_{2}$}

\section{Gambar 3.1. Rumus pre-experimental one- group pretest-posttest design}

Dalam pelaksanaan ekperimen menggunakan desain subyek tunggal dengan memberikan tes kepada subjek yang belum diberi perlakuan disebut pre test $\mathrm{O} 1$ untuk mendapatkan nilai arus inrush sebelum penambahan reaktor seri.

Setelah memiliki masalah dalam besar nilai arus inrush yang melebihi batas standar IEEE Std C37.012-2005, maka dilakukan treatment (X) dengan penambahan reaktor seri. Setelah dilakukan perlakuan kepada arus inrush yang melebihi batas standart IEEE Std C37.012-2005, dalam post test $\mathrm{O} 2$ akan didapatkan hasil dari eksperimen apakah ada perubahan arus inrush sesuai standar IEEE Std C37.012-2005 atau tidak. Membandingkan $\mathrm{O} 1$ dan $\mathrm{O} 2$ untuk menentukan seberapa besar perbedaan yang timbul.

\section{HASIL DAN PEMBAHASAN Hasil Penelitian}

Berdasarkan penelitian yang dilakukan untuk mengetahui arus inrush saat switching pada kapasitor bank. Data ini diperoleh melalui data pembebanan harian setiap jam.

Untuk mencari nilai arus inrush membutuhkan data pembebanan, tegangan sumber, frekuensi sumber, kapasitas total kapasitor, data sheet kabel, induktansi sumber ke bus, induktansi bus, Induktansi pada kabel, induktansi pada antara switch dengan kapasitor bank yang dimana data tersebut didapatkan dari hasil wawancara dan dari data peralatan di Gardu Induk Gandul.

\section{Data Hasil Penelitian}

\begin{tabular}{|c|c|c|c|c|}
\hline Tabel & & eput & ail & a reaktif \\
\hline $\begin{array}{c}\text { Jam } \\
\text { (WIB) }\end{array}$ & $\begin{array}{c}\text { Faktor } \\
\text { Daya } \\
1 \\
\end{array}$ & $\begin{array}{c}\text { Faktor } \\
\text { Daya } \\
2 \\
\end{array}$ & $\begin{array}{l}\text { Beban } \\
\text { (MW) }\end{array}$ & $\begin{array}{c}\text { Daya } \\
\text { Reaktif } \\
\text { (MVAR) }\end{array}$ \\
\hline 01.00 & 0,85 & 0,90 & 36,65 & 4,68 \\
\hline 02.00 & 0,85 & 0,90 & 34,09 & 4,63 \\
\hline 03.00 & 0,85 & 0,90 & 33,04 & 4,56 \\
\hline 04.00 & 0,85 & 0,90 & 31,81 & 4,10 \\
\hline 05.00 & 0,85 & 0,90 & 31,32 & 4,17 \\
\hline 06.00 & 0,85 & 0,90 & 32,50 & 4,31 \\
\hline 07.00 & 0,85 & 0,90 & 32,83 & 4,26 \\
\hline 08.00 & 0,85 & 0,90 & 31,54 & 4,48 \\
\hline 09.00 & 0,83 & 0,90 & 31,72 & 5,53 \\
\hline 10.00 & 0,83 & 0,90 & 32,82 & 5,63 \\
\hline 11.00 & 0,83 & 0,90 & 33,49 & 6,09 \\
\hline 12.00 & 0,82 & 0,90 & 34,01 & 6,73 \\
\hline 13.00 & 0,82 & 0,90 & 34,97 & 7,07 \\
\hline 14.00 & 0,82 & 0,90 & 35,74 & 6,39 \\
\hline 15.00 & 0,83 & 0,90 & 36,74 & 7,12 \\
\hline 16.00 & 0,83 & 0,90 & 36,94 & 6,96 \\
\hline 17.00 & 0,83 & 0,90 & 37,61 & 6,94 \\
\hline 18.00 & 0,83 & 0,90 & 38,24 & 7,11 \\
\hline 19.00 & 0,84 & 0,90 & 39,78 & 6,53 \\
\hline 20.00 & 0,85 & 0,90 & 43,14 & 6,22 \\
\hline 21.00 & 0,85 & 0,90 & 43,05 & 6,19 \\
\hline 22.00 & 0,85 & 0,90 & 43,18 & 5,89 \\
\hline 23.00 & 0,85 & 0,90 & 41,70 & 5,59 \\
\hline 24.00 & 0,85 & 0,90 & 39,32 & 5,35 \\
\hline
\end{tabular}

3. Perhitungan nilai arus inrush dan frekuensi saat switching kapasitor bank

Dalam menentukan besarnya nilai arus inrush dan frekuensi saat switching kapasitor bank di Gardu Induk Gandul memerlukan data-data di Gardu Induk tersebut. Data-data yang diperlukan untuk menganalisis adalah sebagai berikut:

1. Tegangan Sumber $=20 \mathrm{kV}$

2. Frekuensi Sumber $f_{s} \quad=50 \mathrm{~Hz}$

3. Jumlah Step $=6$

4. Panjang konduktor antara bus dengan sumber $l_{s} \quad=80 \mathrm{~m}$

5. Panjang konduktor antara switch pada kapasitor bank 1 dengan switch pada kapasitor bank $2=5 \mathrm{~m}$

6. Panjang konduktor antara switch dengan kapasitor bank $\quad=2,5 \mathrm{~m}$

7. Induktansi sumber $=9,8 \mu \mathrm{H}$

4. Menghitung induktansi Rangkaian

$$
\begin{aligned}
L_{S-B} & =\left(l_{s}\right) \times\left(L_{t}\right) \\
& =80 \mathrm{~m} \times 0,483 \mu \mathrm{H} / \mathrm{m} \\
& =38,64 \mu \mathrm{H}
\end{aligned}
$$




$$
\begin{aligned}
& =5 \mathrm{~m} \times 0,782 \mu \mathrm{H} / \mathrm{m} \\
& =3,91 \mu \mathrm{H}
\end{aligned}
$$

$L_{1}, L_{2}, L_{3}, L_{4}, L_{5}, L_{6}, L_{7}=\left(\left(l_{s-c}\right) \times\left(L_{t}\right)\right)+$ $5 \mu \mathrm{H}$

$\mu \mathrm{H}$

$$
=(2,5 \mathrm{~m} \times 0,483 \mu \mathrm{H} / \mathrm{m})+5
$$

$$
=6,2075 \mu \mathrm{H}
$$

$5 \mu \mathrm{H}$ merupakan nilai toleransi induktansi untuk kapasitor bank yang dipasang dibawah tegangan $52 \mathrm{kV}$ berdasarkan IEEE Std C37.012-2005

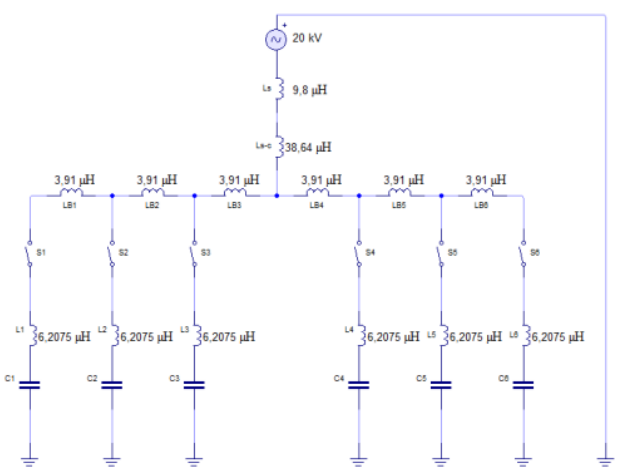

Gambar 4.1. Konfigurasi rangkaian pengganti kapasitor bank

\section{Menghitung Nilai Arus Inrush dan Frekuensi saat Switching Kapasitor Bank}

Untuk menentukan nilai arus inrush dan frekuensi dari keseluruh kapasitor bank. Besar nilai total kapasitor bank adalah 50 MVAR dan masing-masing step adalah 3,55 MVAR. Dari data-data yang diperoleh dapat dihitung arus dasar kapasitor bank ( $I_{\text {dasar }}$ ) (kapasitor ideal atau murni dimana $\sin \varphi=90^{\circ}$ )

$$
\begin{aligned}
I_{\text {dasar }} & =\frac{Q_{c}}{\sqrt{3} \cdot V_{n} \cdot \sin \varphi} \\
& =\frac{3,55 \times 10^{6}}{\sqrt{3} \cdot 20 \cdot 10^{3} \cdot \sin 90^{\circ}} \\
& =102,5 \mathrm{~A}
\end{aligned}
$$

Untuk menentukan arus inrush dan frekuensi dari kapasitor bank yang berjumlah 6 step dengan cara sebagai berikut:

1. Kondisi kesatu (insolated), hanya kapasitor $\mathrm{C} 1$ yang bekerja maka arus inrush dan untuk kapasitor yang ditanahkan dengan faktor pengali 1,35 .

$$
\begin{gathered}
L_{e q 1} \quad=L_{1}+L_{B 1}+L_{B 2}+L_{B 3}+L_{S-C}+L_{S} \\
=6,2075+3,91+3,91+3,91+38,64+9,8 \\
=66,38 \mu \mathrm{H} \\
\begin{aligned}
I_{s c}= & \frac{V}{\omega L_{e q 1}}=\frac{20 \times 10^{3}}{2 \times \pi \times 50 \times 66,38 \times 10^{-6}} \\
& =959.540,03 \mathrm{~A}=959,54 \mathrm{kA}
\end{aligned}
\end{gathered}
$$$$
I_{i} \quad=1,35 \cdot I_{\text {dasar }}
$$

$$
\begin{aligned}
& =1,35 \times 102,5 \\
& =138,37 \mathrm{~A}
\end{aligned}
$$

Besar arus inrush

$$
\begin{aligned}
I_{\text {imax }} & =\sqrt{2} \sqrt{I_{s c} \cdot I_{i}} \\
& =\sqrt{2} \sqrt{959.540,03 \times 138,37} \\
& =16.295,49=16,29 \mathrm{kA}
\end{aligned}
$$

Sedangkan frekuensi maksimum dihintung

$$
\begin{aligned}
f_{i} & =f_{s} \sqrt{\frac{I_{s c}}{I_{\text {dasar }}}} \\
& =50 \sqrt{\frac{959.540,03}{138,37}} \\
& =4163,71 \mathrm{~Hz} \\
& =4,16 \mathrm{kHz}
\end{aligned}
$$

2. Kondisi kedua (back to back) kapasitor C2 bekerja sementara kapasitor $\mathrm{C} 1$ masih kondisi bekerja, maka arus inrush dapat dihitung

$$
\begin{gathered}
L_{e q 2}=\left(\frac{\left(L_{1}+L_{B 1}\right) L_{2}}{\left(L_{1}+L_{B 1}\right)+L_{2}}\right)+L_{B 2}+L_{B 3} \\
+L_{s-c}+L_{s} \\
L_{e q 2}=\left(\frac{(6,2075+3,91) 6,2075}{(6,2075+3,91)+6,2075}\right)+3,91 \\
+3,91+38,64+9,8 \\
=60,1 \mu \mathrm{H}
\end{gathered}
$$

Dengan $I_{1}=I_{2}=138,37 \mathrm{~A}$

$$
\begin{aligned}
I_{\text {imax }} & =13500 \times \sqrt{\frac{U_{r} \cdot I_{1} \cdot I_{2}}{f_{s} \cdot L_{e q} \cdot\left(I_{1}+I_{2}\right)}} \\
& =13500 \times \sqrt{\frac{20 \cdot 10^{3} \cdot 138,37 \cdot 138,37}{50.60,1 \cdot(138,37+138,37)}} \\
& =289.689,3 \mathrm{~A}=289,7 \mathrm{kA}
\end{aligned}
$$

Sedangkan frekuensi maksimum dihitung

$$
\begin{aligned}
f_{i} & =9,5 \sqrt{\frac{f_{s} \cdot U_{r} \cdot\left(I_{1}+I_{2}\right)}{L_{e q} \cdot\left(I_{1} \cdot I_{2}\right)}} \\
& =9,5 \sqrt{\frac{50 \cdot 20 \cdot 10^{3} \cdot(138,37+138,37)}{60,1 \cdot(138,37.138,37)}} \\
& =147,32 \mathrm{kHz}
\end{aligned}
$$

Tabel 4.2. Hasil perhitungan arus inrush dan frekuensi kapasitor pada setiap step

\begin{tabular}{ccccc}
\hline $\begin{array}{c}\text { Kondis } \\
\mathrm{i}\end{array}$ & $\begin{array}{c}L_{e q} \\
(\mu \mathrm{H})\end{array}$ & $\begin{array}{c}I_{s c} \\
(\mathrm{kA})\end{array}$ & $\begin{array}{c}I_{\text {imax }} \\
(\mathrm{kA})\end{array}$ & $\begin{array}{c}f_{i} \\
(\mathrm{kHz})\end{array}$ \\
\hline Ke 1 & $\begin{array}{c}66,3 \\
8\end{array}$ & 959,54 & 16,29 & 4,16 \\
& 8 & & 289,7 & 147,3 \\
$\mathrm{Ke} 2$ & 60,1 & - & & 2 \\
& 55,1 & & & \\
$\mathrm{Ke} 3$ & 4 & - & 349,22 & 133,2 \\
& 54,5 & - & & 126,2 \\
$\operatorname{Ke} 4$ & 3 & - & 372,47 & 8
\end{tabular}




$\begin{array}{ccccc}\text { Ke } 5 & 54,1 & - & 386,03 & 122,7 \\ & 5 & & 410,14 & 125,1 \\ \text { Ke } 6 & 49,9 & - & 6 & 5 \\ & 7 & & 6\end{array}$

Tabel 4.3. Nilai arus inrush maksimum yang diijinkan menurut IEEE Std C37.012-2005

\begin{tabular}{cccc}
\hline Step & \multicolumn{2}{c}{ Aktual } & Standart \\
& Irms & Imax & IEEE Std \\
& $(\mathrm{A})$ & $(\mathrm{kA})$ & $\begin{array}{c}\text { C37.012- } \\
2005 \\
\end{array}$ \\
& & & \\
& & & \\
\hline 1 & 138,37 & 16,29 & 13,84 \\
2 & 276,74 & 289,7 & 27,67 \\
3 & 415,11 & 349,22 & 41,51 \\
4 & 553,48 & 372,47 & 55,35 \\
5 & 691,85 & 386,03 & 69,18 \\
6 & 830,22 & 410,146 & 83,02 \\
\hline
\end{tabular}

\section{Menentukan Kapasitas Reaktor untuk Mereduksi Arus Inrush Pada Kapasitor \\ Bank}

Kapasitas reaktor seri yang digunakan harus digunakan sesuai dengan standar international JIS-C-4092 yaitu 6\% dari reaktansi kapasitor yang dipasang, maka

a. Kapasitansi kapasitor

$$
\begin{array}{ll}
\mathrm{C}=42,92 \mu \mathrm{F} & \\
X_{C}=\frac{1}{2 . \pi \cdot f \cdot C} & \\
X_{C}=\frac{1}{2 . \pi .50 .42,99 \mu}=74,2 \Omega \\
\text { Sehingga: } \\
\frac{X_{L}}{X_{C}} x 100 \% & =6 \% \\
\frac{X_{L}}{74,2} x 100 \% & =6 \% \\
X_{L} & =4,452 \Omega \\
X_{L} & =2 \pi \mathrm{fL} \\
4,452 & =314 \mathrm{~L} \\
\mathrm{~L} & =14.178 \mu \mathrm{H}
\end{array}
$$

b. Menentukan kapasitas rating seri dihitung dalam KVAR

$$
\begin{aligned}
Q_{3 \emptyset} & =3 \cdot\left(I_{\text {dasar }}\right)^{2} \cdot X_{L} \frac{1}{1000} \\
& =3 \cdot(102,5)^{2} \cdot 4,452 \cdot \frac{1}{1000} \\
& =140,32 \mathrm{KVAR}
\end{aligned}
$$

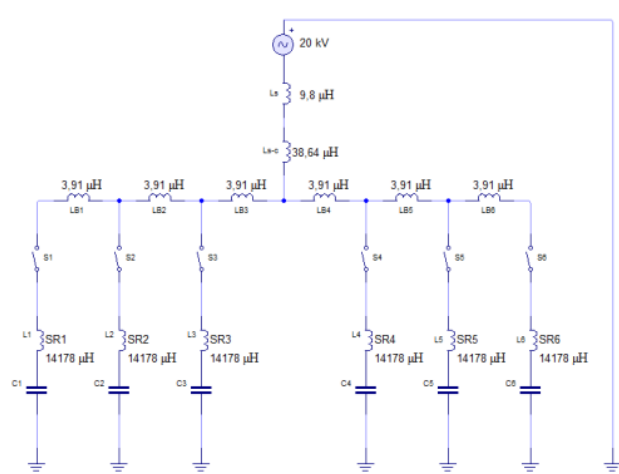

Gambar 4.2. Konfigurasi rangkaian pengganti setelah penambahan reaktor seri

7. Menghitung Nilai Arus Inrush dan Frekuensi saat Switching Kapasitor Bank Setelah Penambahan Reaktor Seri

Untuk menentukan arus inrush dan frekuensi maksimum setelah penambahan reaktor seri $14178 \mu \mathrm{H}$ adalah sebagai berikut: 1. Kondisi kesatu (insolated), hanya kapasitor $\mathrm{C} 1$ yang bekerja maka arus inrush dihitung dan untuk kapasitor bank yang ditanahkan dengan faktor pengali 1,35 .

$$
\begin{aligned}
& L_{e q 1}=\left(L_{1}+L_{S R 1}\right)+L_{B 1}+L_{B 2}+L_{B 3}+ \\
& L_{S-C},+L_{S} \\
& \quad=(6,2075+14.178)+3,91+3,91+3,91 \\
& +38,64+9,8 \\
& \quad=14.244,37 \mu \mathrm{H} \\
& I_{s c}=\frac{V}{\omega L_{e q 1}} \\
& =\frac{20 \times 10^{3}}{2 \times \pi \times 50 \times 14.244,37 \times 10^{-6}} \\
& =4.471,53 \mathrm{~A}=4,47 \mathrm{kA} \\
& \begin{aligned}
& I_{i} \quad=1,35 . I_{\text {dasar }} \\
&= 1,35 \times 102,5 \\
&=138,37 \mathrm{~A}
\end{aligned}
\end{aligned}
$$

Besar arus inrush dihitung

$$
\begin{aligned}
I_{\text {imax }} & =\sqrt{2} \sqrt{I_{s c} \cdot I_{i}} \\
& =\sqrt{2} \sqrt{4.471,53 \times 138,37} \\
& =1.112,4 \mathrm{~A}=1,1 \mathrm{kA}
\end{aligned}
$$

Sedangkan frekuensi maksimum dihintung

$$
\begin{aligned}
f_{i} & =f_{s} \sqrt{\frac{I_{s c}}{I_{i}}} \\
& =50 \sqrt{\frac{4.471,53}{138,37}} \\
& =284,23 \mathrm{~Hz} \\
& =0,2 \mathrm{kHz}
\end{aligned}
$$

2. Kondisi kedua (back to back) kapasitor C2 bekerja sementara kapasitor C1 masih 
kondisi bekerja, maka arus inrush dapat dihitung

$$
\begin{aligned}
& L_{e q 2}=\left(\frac{\left(L_{1}+L_{S R 1}+L_{B 1}\right) L_{S R 2}}{\left(L_{1}+L_{S R 1}+L_{B 1}\right)+L_{S R 2}}\right)+L_{B 2}+L_{B 3} \\
& +L_{s-c}+L_{s} \\
& I_{\text {imax }}=13.500 \mathrm{x} \sqrt{\frac{U_{r} \cdot I_{1} \cdot I_{2}}{f_{s} \cdot L_{e q} \cdot\left(I_{1}+I_{2}\right)}} \\
& =13.500 \times \sqrt{\frac{20 \cdot 10^{3} \cdot 138,37 \cdot 138,37}{50.7 \cdot 149,34 \cdot(138,37+138,37)}} \\
& =26.560,53 \mathrm{~A}=26,56 \mathrm{kA}
\end{aligned}
$$

Sedangkan frekuensi maksimum dihitung

$$
\begin{aligned}
f_{i} & =9,5 \sqrt{\frac{f_{s} \cdot U_{r} \cdot\left(I_{1}+I_{2}\right)}{L_{e q} \cdot\left(I_{1} \cdot I_{2}\right)}} \\
& =9,5 \sqrt{\frac{50 \cdot 20 \cdot 10^{3} \cdot(138,37+138,37)}{7 \cdot 149,34 \cdot(138,37 \cdot 138,37)}} \\
& =13,5 \mathrm{kHz}
\end{aligned}
$$

Tabel 4.4. Hasil perhitungan arus inrush dan frekuensi setiap step setelah penambahan reaktor seri

\begin{tabular}{ccccc}
\hline Kondisi & $L_{e q}(\mu \mathrm{H})$ & $\begin{array}{c}I_{s c} \\
(\mathrm{kA})\end{array}$ & $\begin{array}{c}I_{\text {imax }} \\
(\mathrm{kA})\end{array}$ & $\begin{array}{c}f_{i} \\
(\mathrm{kHz})\end{array}$ \\
\hline $\mathrm{Ke} 1$ & $14.244,37$ & 4,47 & 1,1 & 0,2 \\
$\mathrm{Ke} 2$ & $7.149,34$ & - & 26,56 & 13,5 \\
$\mathrm{Ke} 3$ & 7144,17 & - & 30,68 & 11,7 \\
$\mathrm{Ke} 4$ & 5725,76 & - & 36,35 & 12,3 \\
$\mathrm{Ke} 5$ & 4780,16 & - & 41,08 & 13,05 \\
$\mathrm{Ke} 6$ & 4100,84 & - & 45,27 & 13,8 \\
\hline
\end{tabular}

\section{KESIMPULAN DAN SARAN}

\section{Kesimpulan}

1. Hasil penelitian menunjukan arus inrush saat switching kapasitor bank sebelum penambahan reaktor seri melebihi standart IEEE Std C37.012-2005 dimana arus inrush yang di ijinkan 100 kali arus rms.

2. Besar nilai arus inrush dan frekuensi pada setiap step sebelum penambahan reaktor seri sebesar: step $1=16,29 \mathrm{kA}, 4,16 \mathrm{kHz}$; Step 2 $=289,7 \mathrm{kA}, 147,32 \mathrm{kHz}$; Step $3=349,22 \mathrm{kA}$, $133,2 \mathrm{kHz}$; Step $4=372,47 \mathrm{kA}, 126,28 \mathrm{kHz}$; Step $5=386,03 \mathrm{kA}, 122,7 \mathrm{kHz}$; Step $6=$ $410,146 \mathrm{kA}, 125,15 \mathrm{kHz}$.

3. Besar nilai arus inrush dan frekuensi pada setiap step setelah penambahan reaktor seri sebesar: step $1=1,1 \mathrm{kA}, 0,2 \mathrm{kHz}$; Step $2=$ 26,56 kA, 13,5 kHz; Step $3=30,68$ kA, 11,7
kHz; Step $4=36,35$ kA, 12,3 kHz; Step $5=41,08 \mathrm{kA}, 13,05 \mathrm{kHz}$; Step $6=45,27$ $\mathrm{kA}, 13,8 \mathrm{kHz}$. Sehingga arus inrush sesuai dengan standart IEEE Std C37.012-2005.

\section{SARAN}

Penulis ini memiliki saran sebagai berikut:

1. Pada analisis arus inrush saat switching kapasitor bank pada busbar 2 di Gardu Induk Gandul perlu diadakan tindakan jika terjadi arus inrush yang melebihi standar pada kapasitor bank.

2. Dilakukan pengecekan secara berkala pada kapasitor bank untuk melihat kondisi peralatan.

3. Penelitian selanjutnya diharapkan menggunakan penelitian ini sebagai referensi atau contoh penelitian yang mungkin dapat dijadikan acuan dan dikembangkan lebih baik lagi.

\section{DAFTAR PUSTAKA}

Adif, Mohammad. (2014). Analisis arus inrush saat switching kapasitor bank di Gardu Induk (GI) Manisrejo Madiun. Jurnal mahasiswa TEUB, 2:5.

Adif, Mohammad. (2014). Analisis arus inrush saat switching kapasitor bank di Gardu Induk (GI) Manisrejo Madiun [skripsi]. Malang: Fakultas Teknik, Universitas Brawijaya.

ANSI/IEEE C37.012-1979. IEEE Application Guide for Capacitance Current Switching for AC High-Voltage Circuit Breakers Rated on Symmetrical Current Basis, New York: ANSI/IEEE.

Budiman, Arif Rahmat. (2018). Analisis pengaruh penggunaan kapasitor bank terhadap rugi-rugi daya listrik saluran transmisi pada busbar 1. [skripsi]. Jakarta: Fakultas Teknik, Universitas Negeri Jakarta.

Eko, Hendik, Chusna Arif, Yahya. Sudiharto, Indhana. (2010). Teknik pengurangan arus inrush dan pengurangan 
harmonisasi pada kapasitor bank untuk beban non linier.

Frebiandi, Doni (2018). Analisis arus inrush akibat switching kapasitor bank di Gardu Induk Sragen [skripsi]. Surakarta: Fakultas Teknik, Universitas Muhammadiyah Surakarta.

IEEE Std C37.012-2014. IEEE Guide for the Application of Capacitance Current Switching for AC High-Voltage Circuit Breakers Above 1000, New York: IEEE.

IEEE Std C37.012-2005. IEEE Application Guide For Capacitance Current Switching for AC High Voltage Circuit Breaker, New York: IEEE.

IEEE Std 1036 1992. IEEE Guide for Application of Shunt Power Capacitance, New York: IEEE.

Mayasari, Fitriyani. (2009). Analisis Transient akibat pengaruh switching kapasitor bank dan metode penanggulangannya. Jurnal
Ilmial "Elektrikal Enjiniring" UNHAS, $7: 1$.

Nugroho, Budi. (2015). Pengaruh capasitor bank terhadap kestabilan faktor daya di PLT Biomassa Bantar Gebang [skripsi]. Jakarta: Fakultas Teknik, Universitas Negeri Jakarta.

Pabla, AS (1981). Sistem Distribusi Daya Listrik. Terjemahan oleh Hadi, Abdul. 1994. Jakarta: Erlangga.

PT. PLN (Persero), "Buku Pedoman Pemeliharaan Kapasitor", PT. PLN, 2014.

Sugiyono (2015). Metode Penelitian Kuantitatif Kualitatif dan R\&D. Bandung: Alfabeta.

T. Longland C, T W Hunt \& A Brecknell (1989). Power Capacitor Hand Book. London: Butterworth \& G. Utd. 